\title{
Ideologia e comportamento político no eleitorado brasileiro
}

$\begin{array}{r}\text { Carlos Oliveira } \\ \text { Mathieu Turgeon } \\ \hline\end{array}$

\section{Introdução}

Saber claramente os significados das ideologias políticas, para que servem, como são aplicadas ao cotidiano político, parece ser um extraordinário desafio, principalmente para o amplo eleitorado brasileiro. No restrito ambiente das elites políticas do país, porém, as ideologias tendem a ser ferramentas substanciais na demarcação de preferências políticas, econômicas e morais. Essa elite política, no entanto, não é composta por todos os filiados a um determinado partido político, por todos os políticos, mas pela elite da elite, isto é, os fundadores, diretores, personalidades-chave dos partidos $^{1}$. São os que se alicerçam nas ideologias, e não parecem capazes de extrapolar o ambiente endógeno e influenciar, a partir das ideologias, o comportamento político da grande maioria das pessoas.

É verdade que são poucos os estudos na ciência política brasileira que se debruçam mais minuciosamente sobre a influência das ideologias no âmbito exclusivo do eleitorado. Há no trabalho de Lavareda (1999) uma associação - pelo eleitor - das ideologias a personalidades políticas. Singer (2002) e Carreirão (2002) concluem ser as ideologias importantes preditivos da escolha do voto e preferência por um ou outro partido. Na visão de Singer, esquerda e direita importam para o comportamento político do eleitorado como um todo, enquanto Carreirão encontra evidências de que são influentes apenas para a parcela mais educada. Tarouco e Madeira (2013, p. 161), por sua vez, discutem a possibilidade de que as novas gerações de eleitores possam ter reduzido a disputa em torno das tradicionais diferenças ideológicas de esquerda e direita.

Por outro lado, Almeida (2001) afirma não ser possível assegurar que as ideologias sejam preditivas do comportamento político do eleitorado do Brasil. Não a partir da tradicional escala de autoposicionamento ideológico comum aos surveys sobre a temática. Posicionar-se numa escala dizendo-se de esquerda ou direita, diz ele, não significa que a pessoa saiba o que realmente representam esses termos na política. Almeida (p. 122) sugere, para saber se realmente a ideologia importa para o eleitor, um índice que seja baseado numa combinação de perguntas. Essa é a direção que adotamos, em parte, neste artigo, porque somente uma possível correlação do voto

\footnotetext{
${ }^{1}$ Para mais sobre o assunto ver: Higley e Pakulski (2012) e Vergara (2013). 
com a ideologia declarada não parece suficiente para afirmar que ela importa para o eleitor.

Noutras palavras, quando o eleitor se diz esquerdista ou direitista, é preciso avaliar se esses vocábulos possuem algum sentido político para ele, se fazem diferença na maneira como ele entende a política e, em seguida, como se comporta politicamente. O esperado é que a ideologia paute, constrinja, todas as atitudes políticas de quem as diz possuir. A constrição existe quando há, de fato, correlação entre ideologia e preferências políticas (Converse, 1964). Para a ideologia exercer algum efeito sobre o voto ou preferência partidária, é necessário primeiro verificar se ela ajuda a estruturar o pensamento político dos eleitores como um todo. Esse é o nosso ponto de interesse, a partir do qual pretendemos contribuir com o debate sobre ideologias no Brasil. Procura-se responder neste artigo, crucialmente, à seguinte pergunta: as ideologias políticas esquerda e direita são importantes para o eleitorado brasileiro?

A estratégia central aqui se dá em dois focos: por um lado, avalia-se o percentual do eleitorado brasileiro que expressa sua ideologia. Por outro, a meta é detectar se tal posicionamento declarado é coerente, capaz de estruturar as preferências políticas do eleitor. Isto é, o eleitor brasileiro que se posiciona à esquerda apoia políticas públicas tradicionalmente vinculadas a esse espectro? E o que se diz direitista? Ele é realmente a favor das iniciativas políticas defendidas pela direita?

Respostas mais abrangentes a essas questões podem ajudar a compreender melhor o funcionamento da própria democracia brasileira. É possível, assim como em outros países latino-americanos (Ferrer e Velasco, 2013; Harbers, Vries e Steenbergen, 2012; Wiesehomeier e Doyle, 2012; Zechmeister e Corral, 2010), que a rivalidade ideológica seja limitada entre os eleitores do Brasil. O cenário institucional é determinante nesse contexto. É preciso haver um longo e bem estruturado sistema político, partidos fortes, democracia duradoura e eleitores sofisticados politicamente para haver espaço para o antagonismo ideológico (Ames e Smith, 2010; Converse, 1964; Corral e Zechmeister, 2013; Luskin, 1990; Matsubayashi e Turgeon, em andamento). Definitivamente, em geral, esse não tem sido o contexto da América Latina (Saéz, 2004; Karl, 1990), tampouco do Brasil (Ames e Smith, 2010; Braga e Pimentel Jr., 2011; Fleischer, 2007; Samuels, 1997).

Reconhecemos, entretanto, que o eleitorado brasileiro não pode ser considerado como um grupo puramente homogêneo. Certamente, alguns eleitores prestam mais atenção à política que outros e entendem melhor como ela funciona. Isso implica atitudes políticas diferentes. Digamos, alguns eleitores tendem a ser mais sofisticados politicamente que outros. Por essa razão, este artigo busca, também, investigar a relação sofisticação política/posicionamento ideológico entre os eleitores brasileiros. Espera-se que os mais sofisticados se posicionem ideologicamente numa proporção maior que os menos sofisticados. Da mesma forma, presume-se que a sofisticação 
aumente a probabilidade de a ideologia declarada constringir o apoio do eleitor a determinada política pública.

Não podemos deixar de dizer que, conforme Luskin (1987, p. 333-335), sofisticação política é a complexidade cognitiva política, a expertise política. Um indivíduo é politicamente sofisticado na medida em que suas cognições políticas são vastas, muito bem organizadas e capazes de constringi-lo na sua forma de se comportar politicamente. As pessoas sofisticadas possuem interesse por política, votam, são constantes nos eventos políticos, detectam e perseguem os próprios interesses, além de serem menos suscetíveis à agenda midiática e mais racionais. Quanto aos não sofisticados, são aqueles pouco atentos aos próprios interesses, são menos resistentes à manipulação, não possuem aptidão para assuntos políticos, apegam-se aos candidatos, não a ideias etc.

A partir dessa base teórica, os resultados empíricos apresentados neste artigo sugerem que grande parte do eleitorado brasileiro não entende os significados de esquerda e direita. Especificamente, encontramos um completo distanciamento do autoposicionamento ideológico do eleitorado e suas preferências políticas. A ideologia não o constringe quando diz apoiar ou não determinada política pública. Mesmo para os eleitores mais sofisticados politicamente, não há constrição entre ideologia e políticas públicas. Vemos, portanto, que há evidências bem fortes de que a ideologia não estrutura o comportamento político do eleitor brasileiro, seja ele sofisticado ou não.

Devido aos resultados, e à própria maneira de operacionalizar ${ }^{2}$ as variáveis, este artigo dá mais um passo no debate político e acadêmico em torno do papel das ideologias esquerda e direita no Brasil. Igualmente, entendemos que abre portas para novos estudos e ajuda a sedimentar a construção de um método mais acurado para pesquisas sobre o tema. Em vez de associar a coerência ideológica exclusivamente à escolha do voto ou preferência partidária, deve-se considerar se, de fato, a ideologia constringe o eleitor quando ele estrutura todas as suas atitudes políticas.

\section{Ideologia, eleitorado, contexto institucional e opinião pública}

As pessoas, em geral, têm pouco conhecimento sobre política. É isso que a literatura vem sugerindo ao longo dos anos (Bennett, 1989; 1995; Bennett et al., 1996; Converse, 1964, 1970; Delli Carpini e Keeter, 1996; Kinder, 1998; Luskin, 1987, 2002; Price, 1999). No caso dos Estados Unidos, a primeira evidência desse fenômeno foi apontada pela Escola de Columbia (Lazarsfeld, Berelson e Gaudet, 1944). Depois, dos anos 1960 para frente, pesquisadores da Escola de Michigan (Campbell et al., 1960; Converse, 1964, 1970) aprofundaram os estudos e chegaram a conclusão semelhante.

\footnotetext{
${ }^{2}$ Em vez de usarmos apenas as escalas de autoposicionamento ideológico, utilizamos uma combinação de variáveis relacionadas a temas políticos cuja divergência entre esquerdistas e direitistas tradicionalmente é clara. Nesse ponto, a nossa análise assemelha-se ao que sugeriu Almeida (2001, p. 128).
} 
Avançando no debate, Converse (1964) viu que os eleitores norte-americanos, no geral, não consideravam postulados ideológicos comuns ao espectro conservador ou liberal quando escolhiam partidos ou candidatos. Mais que isso, as pessoas se mostravam confusas quanto aos conceitos políticos por trás dos vocábulos conservador e liberal. Esses achados foram base para novas pesquisas (Bishop et al., 1978; Luskin, 1987; Smith, 1989; Sullivan, Pierson e Marcus, 1978), e o consenso em torno dessas conclusões tem se mantido ao longo dos anos (Baker et al., 1996; Bennett, 1989; Delli Carpini e Keeter, 1996; Fournier, 2001; Gordon e Segura, 1997; Klingemann, 1979; Luskin, 1987; Price, 1999). Vale mencionar a pesquisa de Lane (1962), cujos resultados, diferentemente, apresentavam sim o eleitor norte-americano como conhecedor das crenças políticas. Ele, no entanto, não possuía uma amostra suficiente do eleitorado para afirmar com maior precisão suas conclusões.

Alguns estudos recentes, não obstante, argumentam que o conhecimento político profundo acaba não importando muito no momento em que as pessoas tomam decisões políticas (Bowler e Donovan, 1998; Lupia, 1994; Lupia e McCubbins, 1998; Popkin, 1991; Sniderman, Brody e Tetlock, 1991). Os eleitores fazem suas escolhas a partir de atalhos, por exemplo, informações de amigos, instituições que frequentam, grupos que gostam ou não etc. O mal-informado, no final, emula os bem-informados, como dizem Brady e Sniderman (1985) e Sniderman, Brody e Tetlock (1991). Page e Shapiro (1992), na mesma linha, alegam que as pessoas cometem erros nas suas atitudes políticas, mas esses erros são dispersos na totalidade. Seria como se todos os eleitores fossem altamente sofisticados politicamente.

Lodge, Steenbergen e Brau (1995) propõem que os indivíduos podem tomar significativas decisões eleitorais sem saber bem as razões por trás delas. Segundo eles, eleitores processam informações políticas em tempo real, ou seja, eles as assimilam, retêm-nas ou descartam-nas rapidamente. Similarmente, Lau e Redlawsk (1997) defendem que, no caso do voto, a maioria dos eleitores escolhe corretamente, porque poucos mudariam o julgamento se tivessem mais informações ou oportunidades de aprofundar mais a escolha. As tomadas de decisão se dão a partir de alternativas consideradas boas o bastante (Lau, 2003; Simon, 1985).

Por outro lado, um grupo de pesquisadores tem mencionado que a falta de conhecimento político gera importantes distorções nas atitudes políticas individuais e gerais. Simulações estatísticas mostram que o conhecimento político afeta as atitudes e o voto (Althaus, 1998, 2003; Bartels, 1996; Delli Carpini e Keeter, 1996). Gilens (2001), por meio dos tradicionais surveys e experimentos baseados em surveys, observa que o conhecimento detalhado sobre políticas específicas induz os entrevistados a tomar decisões diferentes das que tomariam caso não tivessem tal conhecimento. Uma boa evidência disso são os experimentos chamados Deliberative Polling, por meio dos quais os participantes aprendem e pensam sobre temas políticos. Os resultados apontam que as atitudes mudam frequentemente (Luskin, Fishkin e 
Jowell, 2002). Kuklinski et al. (2001) detectam que a habilidade das pessoas de fazer escolhas entre opções opostas aumenta quando elas são providas de informações corretas.

Além do mais, é cabível ter em conta que a maioria das pessoas não aparenta ter interesse por temas políticos difíceis como ideologia, sobretudo aquelas com pouca informação (Turgeon, 2009). Os achados de Converse (1964), inclusive, revelam não haver constrição ideológica entre os eleitores norte-americanos menos sofisticados. Inglehart e Klingemann (1976) argumentam que noções ideológicas claras são mais comuns entre os eleitores mais sofisticados. Outros estudos envolvendo países da América Latina chegaram a conclusão similar (Corral e Zechmeister, 2013; Ferrer e Velasco, 2013; Harbers, Vries e Steenbergen, 2012; Luna e Zechmeister, 2005).

Quando pensamos a realidade da política brasileira, entendemos não haver as condições esperadas para a ideologia ser ator principal do comportamento político das pessoas. Faltam as bases institucionais, o acesso a informações consistentes, e o próprio interesse da maioria das pessoas por política parece ser limitado. Uma considerável causa para esse cenário estaria no próprio descompasso entre os estatutos dos partidos e suas práticas políticas diárias (Tarouco e Madeira, 2013). Uma variável notável nesse ponto, como diz Zucco Jr. (2011), é o fato de ser governo ou oposição. Segundo ele, se o partido estiver na oposição, move-se para a esquerda; e, se for governo, para a direita. Não há ideologia perene.

Também não existe no Brasil um posicionamento público dos partidos relevantes eleitoralmente à esquerda ou à direita que seja capaz de contagiar ou informar o eleitorado. A exceção, pelo menos até a ascensão de Lula ao poder, é o Partido dos Trabalhadores (Lucas e Samuels, 2011). Lucas e Samuels concluem que o sistema partidário brasileiro não se consolidou de forma que os eleitores possam distinguir ideologias facilmente entre as principais agremiações. Adiciona-se a isso, como aponta Nicolau (2006), o sistema eleitoral de lista aberta, o qual tende a favorecer o candidato em detrimento do partido e acaba deixando de lado questões doutrinárias. A lista aberta é adotada no Brasil desde 1945.

De fato, vê-se no país um cenário político de predomínio das personalidades (Braga e Pimentel Jr., 2011; Kinzo, 2005; Paiva e Tarouco, 2011; Samuels, 1997). Isso pode ser evidenciado no tradicional "troca-troca" de partidos (Ferreira, Batista e Stabile, 2008; Melo, 2004) e pelas coalizões de governo (Meneguello, 2010). Há um problema nessa inconstância porque os partidos políticos, historicamente, são os mais importantes instrumentos de debate e publicização da ideologia (Coppedge, 1997; Huber e Inglehart, 1995; Oppo, 2004). Sua capacidade de influenciar supera o domínio político e invade o terreno econômico, social, familiar, comportamental, enfim (Duverger, 1980). Essa influência não aparenta existir no Brasil, porque, muitas vezes, nem os políticos são fiéis às suas agremiações.

Por isso, por causa da própria conjuntura política brasileira, até para pessoas 
mais sofisticadas, não é fácil estabelecer-se ideologicamente de forma conexa. Portanto, sem dúvida, permanece pertinente a pergunta: será que a ideologia exerce algum papel no comportamento político do eleitorado brasileiro, apesar de sua pouca relevância na estruturação da vida partidária de modo geral?

Nesse sentido, precisamos avaliar primeiro se esses eleitores se autoposicionam ideologicamente. Um eleitorado em que muitos não se autoposicionam não seria evidência favorável à ideia de que a ideologia importa. Autoposicionar-se ideologicamente é um mínimo exigido.

Espera-se, pelas razões teóricas apresentadas aqui, que as pessoas mais sofisticadas possam sim ser mais influenciadas pela ideologia do que as menos sofisticadas. Também é esperado que as mais sofisticadas sejam mais bem preparadas para organizar preferências políticas em função da ideologia indicada. Quer dizer, a ideologia política deve constringir suas atitudes políticas, como entendido por Converse.

\section{Metodologia e dados}

Para avaliar o papel da ideologia no eleitorado brasileiro, usamos dados do Estudo Eleitoral Brasileiro (Eseb) de 2002 e 2010³. A preferência pelo Eseb se deu pela representatividade da amostra e boa compatibilidade dos questionários com a elaboração teórica proposta nesta pesquisa. Não utilizamos o Eseb 2006 por impossibilidade de executar os testes de hipótese com as mesmas variáveis de 2002 e 2010.

No Eseb, a ideologia é mensurada pelo autoposicionamento dos respondentes numa escala de 11 pontos. Especificamente, é solicitado ao entrevistado que se posicione numa escala de 0 a 10 para revelar sua ideologia. Quem marca 0 é reputado extrema esquerda e 10 extrema direita. Os questionários também possuem perguntas adicionais que permitem a operacionalização de outros conceitos de interesse, como a sofisticação política.

\section{Eleitores que se posicionam ideologicamente}

O interesse nesse ponto é puramente descritivo, isto é, expressar o percentual do eleitorado que se posiciona na escala esquerda-direita. Aqui, a novidade em relação aos

\footnotetext{
${ }^{3}$ O Eseb é um estudo vinculado ao projeto internacional Comparative Study of Electoral Systems (CSES), coordenado pela Universidade de Michigan. A onda de 2002 foi realizada a partir de uma parceria entre o Cesop e o DataUff, sob a coordenação da prof. dra. Rachel Meneguello, prof. dr. Fernando Lourenço, prof. dr. Alberto Almeida e prof. dr. Zairo Chei Dub. A onda de 2010 foi coordenada pela prof. dra. Rachel Meneguello (Cesop-Unicamp) e apoiada pelo CNPq. Para informações completas da pesquisa, ver o Apêndice. As bases de dados do Eseb estão disponíveis no Banco de Dados de Pesquisa do Cesop/Unicamp: <www.cesop.unicamp.br/sie/htm/apre.php>. Acesso em: 10 mar. 2012.
} 
trabalhos de Singer (2002) e Carreirão (2002) está na operacionalização das variáveis. Adotamos duas maneiras, ambas como variáveis dicotômicas. Na primeira, todas as posições da escala esquerda-direita são agrupadas como respostas de quem se "Posiciona" (1). Quem indicou não saber ou se recusou a responder à pergunta é classificado como "Não se Posiciona" (0). Na segunda operacionalização, o ponto do meio da escala, no caso o número 5 , também é entendido como "Não se Posiciona" (0).

A intenção, com isso, é dialogar com um importante debate metodológico. Segundo Kroh (2007), existem duas interpretações na literatura a respeito do ponto do meio da escala. Na primeira, estão aqueles que se preocupam em saber se quem se autoposicionou no centro mostra um direcionamento preciso da sua opinião latente ou acaba se escondendo por não apresentar atitude ideológica ou não querer tomar parte. A segunda entende que o ponto do meio oferece uma adicional gradação para mapear opiniões latentes. As pessoas podem mesmo ser de centro.

Converse e Pierce (1986, p. 128) estão entre os que alimentam a controvérsia. Ao estudarem o caso francês, observaram que um quarto dos respondentes se colocaram no ponto do meio da escala. Para eles, essas pessoas são "neutras, descompromissadas ou mesmo completamente indiferentes e ignorantes em relação ao eixo genérico das disputas políticas". Na mesma direção, Narayan e Krosnick (1996) entendem ser as marcações do ponto do meio um indicativo de que o respondente não conhece tão bem o assunto quanto os que se colocam nas outras posições da escala. Scholz e Zuell (2012, p. 1.425), numa pesquisa em que avaliaram situações nas quais os entrevistados que se posicionam ideologicamente estariam propensos a responder questões abertas, observaram que os que se colocaram no meio são os menos dispostos.

Por essa razão, apresentamos os resultados a partir das duas operacionalizações. A Figura 1 mostra a distribuição para os estudos do Eseb de 2002 e 2010: 


\section{Figura 1 \\ Capacidade de se autoposicionar ideologicamente (\%) \\ Eseb 2002 e 2010}

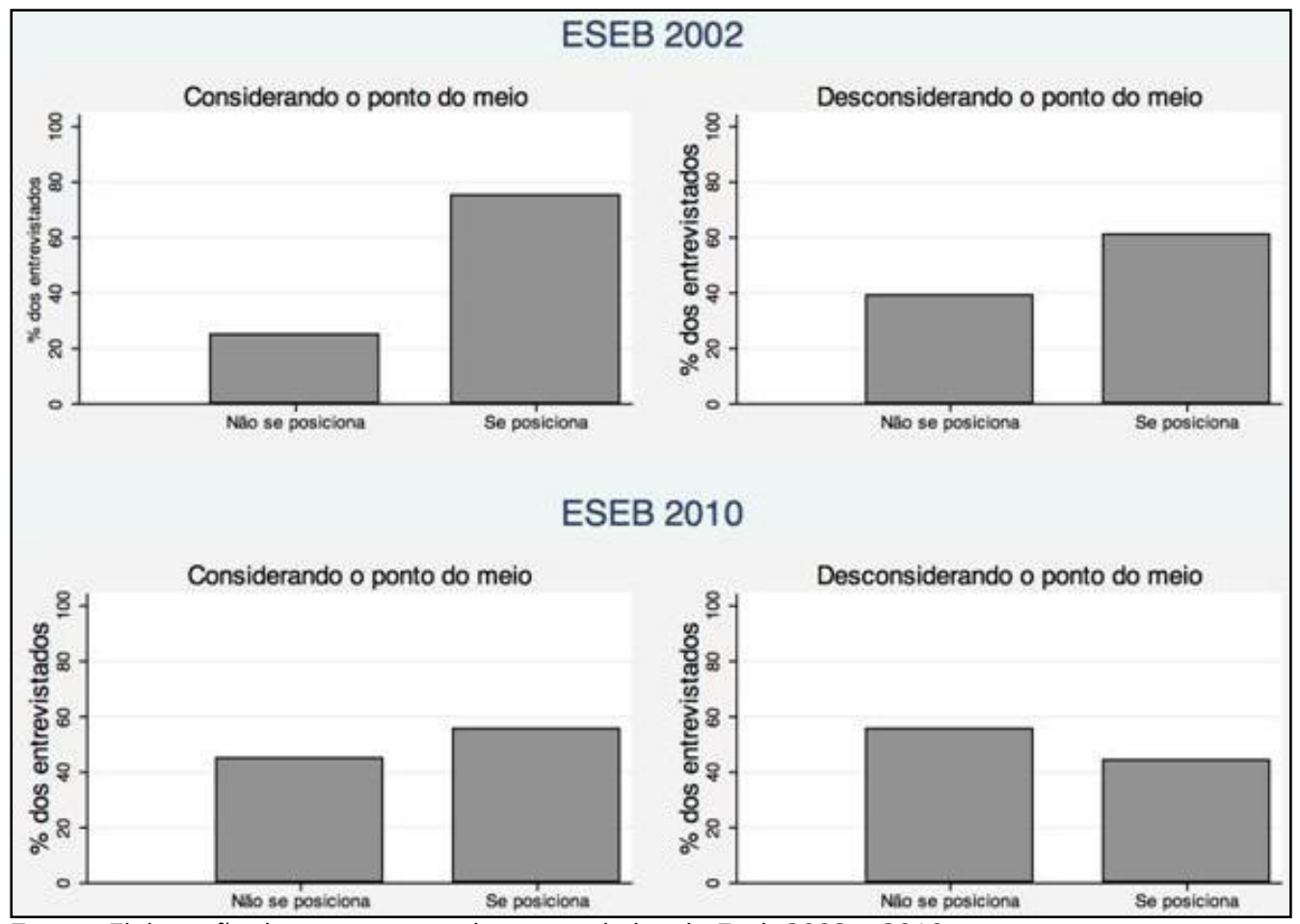

Fonte: Elaboração dos autores com base nos dados do Eseb 2002 e 2010.

Começando com 2002, temos que $74,9 \%$ dos respondentes se posicionaram na escala esquerda-direita. Já se desconsiderarmos o ponto do meio (5) como posicionamento válido, temos que $60,7 \%$ dos respondentes se posicionaram. Os resultados para 2010 indicam que somente $55,2 \%$ dos eleitores se posicionaram, considerando-se a escala por inteiro. O percentual cai para $44,3 \%$ quando rejeitamos o ponto central.

Um achado importante é a patente e considerável redução no percentual de eleitores que se posicionaram de 2002 a 2010. Era de esperar quedas importantes nas porcentagens, principalmente da primeira operacionalização à segunda. Porém, no cenário mais favorável, com todos os pontos da escala levados em conta, observamos uma redução de quase 20 pontos percentuais em 8 anos. É um dado relevante, porque, a título de comparação, nós aplicamos a medida ao survey Cultura Política (realizado pelo Cedec/Datafolha em 1989 sob a coordenação do prof. dr. José Álvaro Moisés $)^{4}$, e

4 Cedec/Datafolha. Pesquisa de Cultura Política (1989). Disponível em: <http://nupps.usp.br/index.php/component/content/article/17-conteudo/menus/37-arquivos-paradownload> Acesso em: 15 out. 2014. 
os resultados da medição naquela época são similares aos do Eseb 2002 com todos os pontos da escala (76\%), e aos do Eseb 2010 sem o ponto do meio (44\%). Singer (2012) e Samuels (2008) argumentam que essa redução no posicionamento ideológico do eleitor brasileiro pode ser resultado da ascensão de Lula à presidência da República. Não é nosso objetivo avaliar o caso Lula sobre o posicionamento ideológico, mas a queda abrupta na atitude de o eleitor se posicionar ideologicamente, especialmente após a vitória dele, é intrigante.

Em suma, voltando ao ponto principal, temos que cerca de 44\%-55\% dos eleitores brasileiros se posicionam na escala esquerda-direta em 2010. Não é um percentual alto se compararmos esses dados, por exemplo, aos do Uruguai e do Chile, cujos números mostram $92,9 \%$ e $88 \%$, respectivamente, segundo Ferrer e Velasco (2013, p. 88). Isso faz todo sentido, pois, de acordo com Luna e Zechmeister (2005), esses países são, entre os latino-americanos, os que possuem a mais vigorosa competição partidária, melhor institucionalização e maior desenvolvimento socioeconômico.

Por fim, como discutido, o posicionamento na escala não é a melhor medida das ideologias no eleitorado, mas esse resultado é um indicativo de que a ideologia não parece ter papel de destaque na estruturação das atitudes políticas do eleitorado do país. Porém, é possível que ela tenha relevância para uma parcela: os eleitores mais sofisticados. Por isso, a seguir, analisamos se a sofisticação política ajuda o eleitor a se posicionar ideologicamente.

\section{As explicações do posicionamento ideológico}

Na literatura sobre formação de atitudes e opiniões políticas, identificamos que os jovens, os menos educados e as mulheres tendem a não expressar opiniões e atitudes políticas em pesquisas de survey, quando comparados aos mais velhos, mais educados e aos homens (Bishop et al., 1978; Schuman e Presser, 1981).

Especificamente, as pessoas mais velhas, na comparação com as mais jovens, teriam mais oportunidades de construir atitudes e opiniões políticas ao longo do tempo por causa da vivência de etapas importantes da vida. Identicamente, as pessoas mais educadas teriam desfrutado, durante seus anos de estudos, de um ambiente de maior capacidade crítica e propício à aprendizagem sobre política. Por isso, seriam mais aptas a elaborar opiniões e atitudes políticas. E os homens ainda, por terem infelizmente mais oportunidades de estudo e de trabalho que as mulheres, teriam vantagem notável sobre elas na construção de opiniões e atitudes políticas.

Por último, consideramos a sofisticação política como o determinante mais importante na concepção de atitudes e opiniões políticas (Althaus, 1996; Krosnick e Milburn, 1990). Baseando-se nessa discussão, espera-se que as pessoais mais velhas, mais educadas, mais sofisticadas e do gênero masculino sejam mais propensas a se 
autoposicionar na escala esquerda-direita.

Para os testes, temos como variável dependente a capacidade de se autoposicionar na escala esquerda-direita como explicado na seção "Eleitores que se posicionam ideologicamente". Consideramos aqui a operacionalização que contabiliza todos os pontos da escala como válidos. Adotamos, por consequência, uma estratégia que não discriminaria indevidamente as pessoas que são realmente centristas. Como variáveis independentes, utilizamos idade das pessoas, grau de formação educacional, gênero e nível de sofisticação política.

No modelo, a idade é simplesmente a idade, como indicado pelo respondente. A educação, por sua parte, é operacionalizada como uma variável dicotômica indicando os respondentes que possuem graduação incompleta até pós-graduação, os quais são codificados (1) e os demais (0). A ideia é distinguir quem possui alguma formação superior do restante. A terceira variável independente é outra dicotômica que diferencia os respondentes homens (1) das mulheres (0).

A sofisticação política é um conceito mais difícil de mensurar. Aqui seguimos as sugestões de Luskin ${ }^{5}$ (1990), as quais são largamente adotadas na disciplina. Mais detalhadamente, Luskin aconselha mensurar a sofisticação política pelo grau de conhecimento político de uma pessoa. Quer dizer, uma pessoa sofisticada é aquela que possui informação política. Seguimos essa recomendação e contabilizamos as respostas corretas às perguntas de conhecimento político aplicadas nos estudos do Eseb.

Por exemplo, no Eseb de 2002 os respondentes foram solicitados a identificar o partido do presidente Fernando Henrique Cardoso. Os respondentes que corretamente indicaram o PSDB receberam um ponto, e os demais, zero. Contabilizamos também a indicação correta, pelos entrevistados, dos partidos e candidatos à presidência na mesma escala esquerda-direita. Os que posicionaram Dilma Rousseff à esquerda de José Serra, ambos candidatos à presidência em 2010, também receberam um ponto e os demais, zero. A Tabela 1 apresenta o resultado da análise multivariada:

\footnotetext{
5 O debate sobre sofisticação política não é algo finalizado, especialmente quanto à sua medição. Preferimos adotar a recomendação de Robert Luskin e outros por entendermos que, devido à complexidade do conceito, a melhor maneira de medi-lo é, ainda, via mensuração do conhecimento político. Para mais discussão sobre o tema, ver Neumann (1986) e, mais recentemente, Mondak (2001), além de Luskin e Bullock (2011).
} 
Tabela 1

Os determinantes da capacidade de se autoposicionar ideologicamente, Eseb 2002 e 2010

\begin{tabular}{|c|c|c|}
\hline & Eseb 2002 & Eseb 2010 \\
\hline & $\begin{array}{c}\text { Coeficiente estimado } \\
\text { (e.-p.) }\end{array}$ & $\begin{array}{c}\text { Coeficiente estimado } \\
\text { (e.-p.) }\end{array}$ \\
\hline Idade & $\begin{array}{r}-0,007^{*} \\
(0,003)\end{array}$ & $\begin{array}{c}-0,001 \\
(0,003)\end{array}$ \\
\hline Homem & $\begin{array}{l}0,526^{*} \\
(0,104)\end{array}$ & $\begin{array}{l}0,372 * \\
(0,105)\end{array}$ \\
\hline Educação superior & $\begin{array}{l}0,989 * \\
(0,247)\end{array}$ & $\begin{array}{l}0,672 * \\
(0,185)\end{array}$ \\
\hline $\begin{array}{l}\text { Sofisticação } \\
\text { política }\end{array}$ & $\begin{array}{l}0,549 * \\
(0,041)\end{array}$ & $\begin{array}{l}0,428^{*} \\
(0,24)\end{array}$ \\
\hline Intercepto & $\begin{array}{c}0,120 \\
(0,151)\end{array}$ & $\begin{array}{l}-2,600^{*} \\
(0,205) \\
\end{array}$ \\
\hline Pseudo- $R^{2}$ & 0,13 & 0,20 \\
\hline $\begin{array}{l}\text { Log. de } \\
\text { verossimilhança }\end{array}$ & $-1229,4$ & $-1098,4$ \\
\hline $\mathrm{N}$ & 2.514 & 1.999 \\
\hline
\end{tabular}

Fonte: Eseb 2002 e 2010.

* Significância: $p<0,05$, teste bicaudal.

As estimativas apresentadas na Tabela 1 foram obtidas pelo estimador de máximo de verossimilhança, adotando a regressão logit. O modelo apresenta níveis razoáveis de ajuste para esse tipo de dados, com pseudo- $R^{2}$ de 0,13 e 0,20 para o Eseb 2002 e 2010, respectivamente. Outra medida indicada para esse tipo de análise é a de avaliar quão bem o modelo prediz corretamente os valores observados da variável dependente. Encontramos que, de forma respectiva, $76 \%$ e $72 \%$ das observações da variável dependente são corretamente preditas pelo modelo para 2002 e 2010. De modo geral, podemos concluir que explicamos relativamente bem o autoposicionamento (ou, inversamente, a falta de autoposicionamento) dos eleitores numa escala esquerdadireita.

Olhando agora as estimativas para as variáveis independentes, encontramos que a idade, contrariamente às expectativas, não é positivamente relacionada ao posicionamento ideológico. A estimativa para o Eseb 2002 indica que as pessoas mais velhas têm, na verdade, menor probabilidade de se autoposicionar. Idade, por outro lado, não apresenta efeito estatisticamente significativo em 2010.

Com respeito às outras variáveis independentes, todas confirmaram as expectativas. Homens, quando comparados a mulheres, têm maior probabilidade de se posicionar. Pessoas que possuem educação superior comparadas com aquelas que não possuem, também têm maior probabilidade de se autoposicionar ideologicamente. $E$, finalmente, pessoas mais sofisticadas politicamente também são mais propensas a se autoposicionar. Note-se que todas as estimativas, menos aquela para idade em 2010, 
são estaticamente significativas ao nível de 0,05.

Entretanto, as estimativas do modelo logit são difíceis de ser interpretadas além do sinal dos efeitos. Elas não fornecem informação nenhuma sobre a substancialidade dos efeitos de cada variável independente. Por isso, calculamos a mudança na probabilidade de se posicionar, a partir de alterações nos valores das variáveis independentes. O procedimento-padrão é calcular a mudança na probabilidade de se posicionar, variando os valores de uma variável independente de interesse e mantendose as outras nos seus valores médios. Seguindo esse procedimento, detectamos que, quando se varia a idade de 25 anos ( $25^{\circ}$ percentil) para 50 anos $\left(75^{\circ}\right.$ percentil), há uma redução na probabilidade de se autoposicionar na escala esquerda-direita de $3 \%$ e $0 \%$ para 2002 e 2010, respectivamente. Em suma, a idade não tem efeito substantivo sobre o posicionamento ideológico.

Fazendo o mesmo exercício para a variável de gênero, encontramos que os homens, quando comparados às mulheres, têm probabilidade maior de se posicionar na escala (de $8 \%$ e $9 \%$ em 2002 e 2010, respectivamente). O efeito do gênero do eleitor é mais substantivo do que aquele da idade, mas ainda é relativamente pequeno. Já o efeito de possuir ou não educação superior, por sua parte, é maior. Eleitores que possuem educação superior teriam, em 2002 e 2010, respectivamente, 13\% e 15\% mais probabilidade de se autoposicionar, na comparação com os que não estão no mesmo nível educacional.

Porém, o efeito mais significativo de todos, em consonância com o esperado, é o da sofisticação política. Mantendo todas as outras variáveis independentes nas suas médias, encontramos que pessoas mais sofisticadas ( $75^{\circ}$ percentil) são $18 \%$ (2002) e $40 \%$ (2010) mais propensas a se posicionar na escala esquerda/direita, quando comparadas às menos sofisticadas $\left(25^{\circ}\right.$ percentil). O efeito dessa variável é incontestável e indica o quão importante é a sofisticação política para explicar grande parte da heterogeneidade das atitudes e comportamentos políticos das pessoas de modo geral (Delli Carpini e Keeter, 1996).

Até agora, chegamos à conclusão de que boa parte do eleitorado brasileiro não se posiciona na escala esquerda-direita. Vimos também que algumas pessoas são mais suscetíveis a se posicionar ideologicamente que outras. Resta saber se aquelas que se posicionaram usam a ideologia para estruturar as suas atitudes ou opiniões políticas, como se espera. Essa é a questão que tentamos responder a seguir.

\section{A ideologia e sua influência sobre as atitudes políticas}

Antes de avaliarmos a relação entre ideologia e atitudes políticas, vejamos como o eleitor brasileiro tem se declarado ao longo dos anos, se à esquerda ou à direita do espectro ideológico. A Figura 2 apresenta a distribuição da ideologia para 2002 e 2010. Os números sugerem que, majoritariamente, o brasileiro se coloca do centro à direita. 
Inclusive, de 2002 a 2010, aumentaram os posicionamentos do ponto do meio (centro) e da direita:

Figura 2

\section{Distribuição da ideologia}

Eseb 2002 e 2010

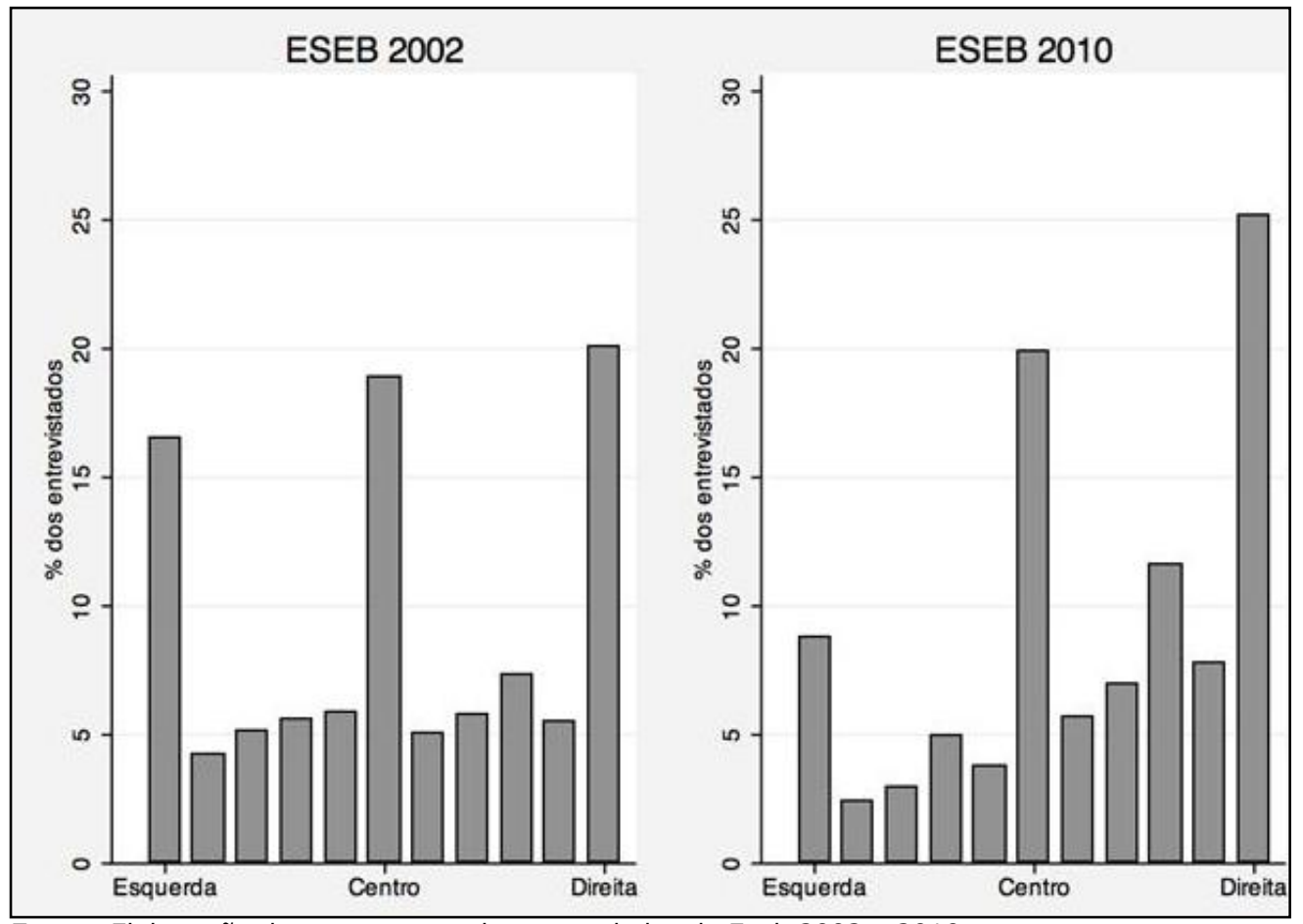

Fonte: Elaboração dos autores com base nos dados do Eseb 2002 e 2010.

O posicionamento médio é de 5,29 e 6,35 em 2002 e 2010, respectivamente, ilustrando o movimento do centro para a direita no intervalo de oito anos. Em 2002, como em 2010, o posicionamento preferido dos brasileiros é o ponto mais à direita da escala, ou seja, o ponto 10 , com $20,1 \%$ e 25,2\%, respectivamente. Em seguida, o ponto com maior frequência é o do centro da escala (5) com 18,9\% e 19,8\%, para 2002 e 2010 respectivamente. Essa tendência mais de centro a direita do eleitorado brasileiro é recorrente desde as medições feitas na década de 1960 e, depois, a partir do final dos anos 1980 (Lavareda, 1999; Singer, 2002).

Agora, vejamos se a ideologia estrutura as preferências políticas do eleitorado. Conforme a ideologia declarada, a hipótese é a de que o eleitor se posicione favorável ou contrariamente a certas políticas, por exemplo, maior ou menor intervenção do Estado na economia. Uma segunda hipótese é a de que essa relação deve ser mais forte 
entre os mais sofisticados. Quanto mais sofisticado politicamente for o eleitor, maior será o efeito da constrição ideológica sobre suas preferências políticas.

Para fazer os testes, utilizamos uma série de variáveis ${ }^{6}$ (Eseb 2002 e 2010) relacionadas à ação, ou não, do Estado em segmentos que vão de educação e saúde a telefonia e indústria, assim como a desapropriação de terras. Os eleitores são questionados sobre quem deveria cuidar desses setores: empresas privadas ou 0 governo. No caso da reforma agrária (só no Eseb 2002), a pergunta é se o eleitor concorda que o governo deve desapropriar terras sem uso. Essas variáveis foram escolhidas porque são temas econômicos e sociais tradicionalmente associados às ideologias políticas, sendo, em resumo, esquerda favorável e direita contrária a maior atuação do Estado.

Para o Eseb 2002, juntamos todas as questões sobre economia e criamos duas novas variáveis dependentes chamadas liberalismo econômico $I$ e liberalismo econômico II. Na primeira, estão 14 perguntas sobre o papel do governo e da iniciativa privada em determinadas áreas econômicas e sociais. Quem respondeu que o governo deve ser preponderante foi codificado (0); se respondeu: ambos, o governo e as empresas, (1); se respondeu: apenas as empresas, (2). Os valores maiores indicam apoio à iniciativa privada.

Já para o segundo grupo de perguntas, os respondentes foram questionados sobre o seu grau de concordância (de concorda muito a discorda muito) com a intervenção do governo em temas econômicos como a fixação dos preços de serviços básicos e salários de trabalhadores. Construímos, dessa vez, uma escala de cinco pontos na qual os valores menores indicam forte apoio à intervenção do governo (1) e valores maiores indicam forte apoio à iniciativa privada (5). Em relação à reforma agrária, criamos uma variável dicotômica codificada assim: (0) para os respondentes que são a favor da desapropriação das terras sem uso e (1) para aqueles que acreditam que os donos da terra devem ter o direito de querer ou não cultivá-la.

As questões do Eseb 2010 foram agrupadas em duas novas variáveis. A primeira, chamada liberalismo econômico III, trata também da intervenção, ou não, do governo em certos setores. Novamente, os respondentes foram perguntados sobre o grau de concordância (de concorda muito a discorda muito) com a intervenção do governo na economia de modo geral. Adotamos também uma escala de cinco pontos na qual os valores menores indicam apoio à intervenção do governo (1) e os valores maiores, apoio à iniciativa privada (5).

E a outra variável dependente trata do papel do governo em redistribuir a renda no Brasil. Chamamos essa variável de redistribuição. Aqui também os respondentes tinham que indicar o seu grau de concordância numa mesma escala de quatro pontos

\footnotetext{
${ }^{6}$ A descrição completa sobre a construção dessas quatro variáveis dependentes, assim como as perguntas dos Eseb 2002 e 2010, encontra-se no Apêndice.
} 
(desconsideramos o ponto do meio e a opção "nem concordo nem discordo"), com os valores menores indicando apoio à ação do governo na redistribuição. Por fim, completamos os modelos de regressão com a adição das seguintes variáveis-controle: idade, gênero e educação ${ }^{7}$.

A ideologia (aqui utilizamos a escala completa, de 0 (esquerda) a 10 (direita)) entra no modelo como variável independente e interage também com a variável sofisticação política. O procedimento de interagir variáveis explicativas é conhecido por modelo interativo, o qual prevê a multiplicação dessas variáveis entre si. A metodologia é bastante adequada aos fenômenos analisados pela ciência política, por causa da relação condicional existente entre contextos institucionais e atores (Brambor, Willian e Golder, 2006).

Por exemplo, como visto na discussão teórica, espera-se haver constrição entre ideologia e preferências políticas. Antevemos, nesse caso, sinal positivo dessa relação, ou seja, pessoas mais à direita preferindo menor papel do governo e que os donos de terra decidam se a cultivam ou não. Inversamente, pessoas mais à esquerda preferindo maior papel do governo na economia e a desapropriação das terras sem uso. Essa relação deve ser mais forte entre os eleitores mais sofisticados. Também esperamos, nesse caso, que a variável de interação entre ideologia e sofisticação política tenha, da mesma forma, um sinal positivo. Portanto, deve haver uma relação mais forte de ideologia e preferências políticas entre as pessoas mais sofisticadas.

Dada a natureza contínua das três variáveis dependentes de liberalismo econômico e da variável redistribuição, adotamos os mínimos quadrados ordinários para estimar os coeficientes dos determinantes destas. Já para a variável dicotômica reforma agrária, os coeficientes da análise multivariada foram estimados pelo máximo de verossimilhança, adotando o modelo logit. Os resultados da estimação dessas regressões estão apresentados na Tabela 2:

\footnotetext{
${ }^{7}$ Detalhes na Tabela A1 do Apêndice.
} 
Tabela 2

Ideologia, sofisticação política

e preferências políticas, Eseb 2002 e $2010^{1}$

\begin{tabular}{|c|c|c|c|c|c|}
\hline & \multicolumn{3}{|c|}{ Eseb 2002} & \multicolumn{2}{|c|}{ Eseb 2010} \\
\hline & $\begin{array}{c}\text { Liberalismo } \\
\text { econômico I } \\
\text { Coef. est. } \\
\text { (e.-p) }\end{array}$ & $\begin{array}{c}\text { Liberalismo } \\
\text { econômico II } \\
\text { Coef. est. } \\
\text { (e.-p.) }\end{array}$ & $\begin{array}{c}\text { Reforma } \\
\text { agrária } \\
\text { Coef. est. } \\
\text { (e.-p.) }\end{array}$ & $\begin{array}{c}\text { Liberalismo } \\
\text { econômico III } \\
\text { Coef. est. } \\
\text { (e.-p.) }\end{array}$ & $\begin{array}{c}\text { Redistribuição } \\
\text { Coef. est. } \\
\text { (e.-p.) }\end{array}$ \\
\hline Ideologia & $\begin{array}{c}-0,05 \\
(0,07) \\
\end{array}$ & $\begin{array}{c}-0,11^{*} \\
(0,06) \\
\end{array}$ & $\begin{array}{l}0,09 * \\
(0,02) \\
\end{array}$ & $\begin{array}{r}-0,10 \\
(0,13) \\
\end{array}$ & $\begin{array}{l}-0,06 \\
(0,04) \\
\end{array}$ \\
\hline $\begin{array}{l}\text { Sofisticação } \\
\text { política }\end{array}$ & $\begin{array}{l}0,40 * \\
(0,17) \\
\end{array}$ & $\begin{array}{c}0,07 \\
(0,13) \\
\end{array}$ & $\begin{array}{l}-0,05 \\
(0,06)\end{array}$ & $\begin{array}{l}-0,10 \\
(0,15)\end{array}$ & $\begin{array}{c}0,04 \\
(0,05) \\
\end{array}$ \\
\hline $\begin{array}{l}\text { Ideologia* } \\
\text { sof. pol. }\end{array}$ & $\begin{array}{c}0,03 \\
(0,03) \\
\end{array}$ & $\begin{array}{c}0,04 \\
(0,02) \\
\end{array}$ & $\begin{array}{l}-0,01 \\
(0,01)\end{array}$ & $\begin{array}{c}0,02 \\
(0,02)\end{array}$ & $\begin{array}{c}0,01 \\
(0,00) \\
\end{array}$ \\
\hline Idade & $\begin{array}{l}-0,02^{*} \\
(0,01)\end{array}$ & $\begin{array}{l}-0,00 \\
(0,01)\end{array}$ & $\begin{array}{l}-0,01^{*} \\
(0,00)\end{array}$ & $\begin{array}{c}0,02 \\
(0,01) \\
\end{array}$ & $\begin{array}{c}0,00 \\
(0,00)\end{array}$ \\
\hline Homem & $\begin{array}{c}0,38 \\
(0,29)\end{array}$ & $\begin{array}{l}0,65^{*} \\
(0,22)\end{array}$ & $\begin{array}{l}-0,46^{*} \\
(0,10)\end{array}$ & $\begin{array}{c}-0,37 \\
(0,30)\end{array}$ & $\begin{array}{l}0,22 * \\
(0,09)\end{array}$ \\
\hline $\begin{array}{l}\text { Educação } \\
\text { superior }\end{array}$ & $\begin{array}{l}2.32 * \\
(0,42) \\
\end{array}$ & $\begin{array}{l}3,45^{*} \\
(0,32) \\
\end{array}$ & $\begin{array}{l}-0,23 \\
(0,14)\end{array}$ & $\begin{array}{l}-0,64 \\
(0,42) \\
\end{array}$ & $\begin{array}{c}0,19 \\
(0,13) \\
\end{array}$ \\
\hline Constante & $\begin{array}{l}7,59 * \\
(0,61) \\
\end{array}$ & $\begin{array}{l}9,49 * \\
(0,47) \\
\end{array}$ & $\begin{array}{c}0,25 \\
(0,20) \\
\end{array}$ & $\begin{array}{l}11,82^{*} \\
(1,27)\end{array}$ & $\begin{array}{l}1,64^{*} \\
(0,39) \\
\end{array}$ \\
\hline $\begin{array}{l}\text { Adj. } R^{2} / \\
\text { Pseudo- }{ }^{2}\end{array}$ & 0,05 & 0,08 & 0,03 & 0,00 & 0,04 \\
\hline $\mathrm{N}$ & 1.758 & 1.805 & 1.834 & 1.466 & 1.813 \\
\hline
\end{tabular}

Fonte: Eseb 2002 e 2010.

1 Todas as entradas foram estimadas com o estimador de mínimos quadrados ordinários, menos aquelas da reforma agrária, que foram estimadas pelo estimador de máximo de verossimilhança, adotando o modelo logit.

*Significância: $p<0,05$, teste bicaudal.

As variáveis de interesse são: ideologia e a variável interativa entre ideologia e sofisticação política. Os resultados, obtidos apenas para aqueles respondentes que se autoposicionaram na escala esquerda-direita, não são muito sugestivos de que a ideologia constrinja as preferências políticas dos brasileiros. Especificamente, a ideologia não tem efeitos estatisticamente significativos em três das cinco variáveis dependentes examinadas. Pior ainda, entre as outras duas, a ideologia apresenta um efeito contrário ao esperado em um dos casos. Precisamente, ideologia tem efeito contrário sobre a variável dependente liberalismo econômico II.

Segundo o efeito estimado, temos que quanto mais à direita menos o indivíduo favorece o papel das empresas (no lugar do governo) na economia. O que é muito estranho pensando-se nos pressupostos teóricos da direita. 0 esperado seria 0 contrário. Porém, o efeito observado é muito pequeno. Temos que a diferença entre um indivíduo de extrema esquerda (0) e um outro de extrema direita (10), mantendo-se os outros fatores constantes, é de apenas 1,1 ponto na escala de 0 a 28 de liberalismo econômico, ou seja, a preferência para maior papel do governo (no lugar das empresas) é ligeiramente maior entre os indivíduos de direita. Esse efeito, embora estatisticamente significativo, não é nada substancial. 
O único efeito que ocorre como o esperado para a ideologia é aquele que ela exerce sobre as preferências dos brasileiros com respeito à reforma agrária. No caso, quem estiver mais à direita é contra a desapropriação de terras sem uso. O efeito é estatisticamente significativo, mas, novamente, pouco substancial. A interpretação do coeficiente, nesse caso, não é fácil por ser um coeficiente estimado de um modelo não linear (logit). Esse coeficiente, porém, permite o cálculo de mudança de probabilidade entre desapropriar terras sem uso ou não. O cálculo da mudança de probabilidade entre um indivíduo de extrema esquerda (0) para um outro de extrema direita (10), mantendo-se os outros fatores iguais, é de um aumento de $18 \%$ na probabilidade de preferir a não desapropriação.

E, contrariamente ao esperado, os resultados da Tabela 2 também indicam que os eleitores brasileiros mais sofisticados não são diferentes dos outros. A ideologia não constringe com maior força as preferências políticas deles quando comparados aos menos sofisticados. Precisamente, nenhuma das variáveis interativas entre ideologia e sofisticação política atinge significância estatística. Esperava-se que os coeficientes estimados fossem positivos e estatisticamente significativos, indicando que a ideologia teria um papel maior em constringir as preferências políticas dos mais sofisticados. Porém, todos os coeficientes estimados não são estatisticamente distinguíveis de zero, ou seja, não têm efeito.

Antes de finalizar, todavia, analisamos individualmente os itens que formam as variáveis dependentes para intervenção, ou não, do Estado em vários setores da economia. Isso porque, na primeira operacionalização, agregamos esses itens, tornando-os uma única variável dependente: liberalismo econômico (liberalismo econômico $I$, II e $I I I)$. Como os itens são variáveis discretas, utilizamos aqui o modelo probit ou ordered probit. Nos casos em que há duas opções de respostas, usamos o primeiro. Naqueles com três ou mais, utilizamos o segundo. Tudo estimado pelo máximo de verossimilhança.

Em 2002, das 21 variáveis, ideologia exerce um pequeno efeito negativo para controle pelo Estado dos preços gerais e dos preços básicos, logo, ao contrário do esperado. O mesmo acontece com a questão "o governo deve dizer o que as empresas devem fazer" e também sobre a intervenção estatal no valor dos salários. Para as demais variáveis do grupo, ideologia não é estatisticamente significante em nenhuma. Da mesma forma, contrariamente ao esperado.

A outra variável independente de interesse no modelo é a interação ideologia*sofisticação política. Nesse caso, de todas as 21 variáveis para intervenção do Estado, há um efeito positivo muito pequeno e significância estatística para o setor de carros, controle de preços básicos e sobre o que as empresas devem fazer. Igualmente, o sinal positivo atende aos preceitos teóricos de que os eleitores mais sofisticados e que se posicionam ideologicamente à direita se manifestem quanto à não ação do Estado no mercado. Mas o efeito também é bem pequeno para se inferir algo. 
Em 2010, das 11 variáveis avaliadas, em duas os sinais indicam efeitos negativos e estatisticamente significativos da ideologia sobre elas (privatização e intervenção na autonomia das empresas para demitir). Portanto, contrário ao esperado. Na interação ideologia*sofisticação política, o efeito é o esperado, mas muito pequeno, nas variáveis igualdade, autonomia para demitir, privatização e redistribuição. As outras variáveis não apresentam significância estatística no nível 0,05.

Analisando os resultados para cada item individualmente, vemos que a ideologia, de fato, não parece importante para o comportamento político dos eleitores brasileiros; estes não moldam suas preferências políticas em conformidade com a ideologia que dizem ter.

\section{Considerações finais}

Os achados deste artigo sugerem que o eleitorado brasileiro não compreende a semântica política inerente às ideologias esquerda e direita, apesar de uma parte dele se autoposicionar na escala do espectro ideológico quando responde aos surveys. Mas esse posicionamento não propende a estruturar suas preferências políticas. Mesmo dizendo-se esquerdista ou direitista (nos extremos ou moderado), ele não diferencia quais políticas estão tradicionalmente vinculadas a ambos os espectros. Portanto, se o eleitor não compreende claramente o significado prático das ideologias políticas, não faz sentido afirmar que elas estruturam seu comportamento político.

Esse cenário parece ser resultado da falta de bases institucionais capazes de instigar e fortalecer o debate ideológico. Como mencionamos na discussão teórica, a democracia brasileira é jovem, assim como o sistema partidário, fora as regras eleitorais mais centradas em personalidades. Além disso, os partidos nunca tiveram capilaridade entre o eleitorado. Exatamente o contrário do ambiente esperado para a sedimentação do antagonismo entre ideologias.

A exceção é o Partido dos Trabalhadores (PT), a partir dos anos 1980. O PT tinha um discurso extremado e ideológico enquanto foi oposição até 2002. Isso acabava levando outros partidos com ideologias contrárias a também se posicionarem publicamente. A partir de 2003, com a ascensão de Lula à presidência da República, praticamente desapareceram as disputas ideológicas no Brasil. Não há enfrentamentos extremados como, por exemplo, algum partido político relevante eleitoralmente que defenda fervorosamente a privatização de empresas estatais.

Como notado por outros pesquisadores para o caso da América Latina, o quadro histórico/institucional é preponderante para a ideologia influir no comportamento político do eleitorado. Não é possível afirmar, apenas em função de alguma correlação do voto ou preferência partidária com o autoposicionamento ideológico, que as ideologias guiam o comportamento político do eleitor. Por isso, nosso artigo amplia a discussão sobre o tema e reforça um método mais abrangente de análise do papel da 
ideologia sobre o comportamento político.

Algo importante para futuros trabalhos talvez seja a ampliação do conceito de esquerda e direita, de maneira que temas modernos sejam acrescentados à análise. Uma boa direção pode ser, em vez de considerar apenas tópicos econômicos, incorporar temas como casamento gay, liberalização das drogas, aborto etc. Os debates ideológicos não parecem mais estar vinculados apenas a maior ou menor intervenção do Estado na economia. Assuntos do campo da moral e dos costumes são cada vez mais reais também nos embates políticos da modernidade.

Carlos Oliveira - Pesquisador, Laboratório de Pesquisa em Comportamento Político, Instituições e Políticas Públicas - LAPCIPP, Universidade de Brasília. E-mail: <car.oliveira978@gmail.com>.

Mathieu Turgeon - Professor adjunto, Instituto de Ciência Política - Ipol, Universidade de Brasília. E-mail: <turgeon@unb.br>.

\section{Referências bibliográficas}

ALmEIDA, A. C. "À esquerda dos números, à direita dos fatos". Insight Inteligência, vol. 15, p. 113128, out.-nov.-dez., 2001.

ALTHAUS, S. L. "Opinion polls, information effects and political equality: exploring ideological biases in collective opinion". Political Communication, vol. 13, p. 3-21, 1996.

92, p. 545-558, 1998.

."Information effects in collective preferences". American Political Science Review, vol.

Collective preferences in democratic politics: opinion surveys and the will of the people.

Cambridge, NY: Cambridge University Press, 2003.

AMES, B.; SMITH, E. E. "Knowing left from right: ideological identification in Brazil, 2002-2006". Journal of Politics in Latin America, vol. 3, p. 3-38, 2010.

BAKER, J. R., et al. "Citizen knowledge and perceptions of legislatures in Canada, Britain, and the United States Congress". Journal of Legislative Studies, vol. 2, p. 44-62, 1996.

BARTELS, L. M. "Uninformed voters: information effects in presidential elections". American Journal of Political Science, vol. 40, p. 194-230, 1996.

Bennet, S. E. "Trends in American's Political Information". American Politics Quarterly, vol. 17, p. 422-435, 1989.

259-278, 1995.

"American's knowledge of ideology, 1980-1992". American Politics Quarterly, vol. 23, p.

BennetT, S. E., et al. "Citizen's knowledge of foreign affairs". Press/Politics, vol. 1, p. 10-29, 1996.

Bishop, G. F.; TUChFARber A. J.; Oldendick R. W. "Opinions on fictitious issues: the pressure to answer survey questions". Public Opinion Quarterly, vol. 50, p. 240-250, 1986. 
BISHOP, G. F., et al. "The changing structure of mass belief systems: fact or artifact?". Journal of Politics, vol. 40, p. 781-790, 1978.

Bowler, S.; Donovan, T. Demanding choices: opinion, voting, and direct democracy. Ann Arbour, Michigan: University of Michigan Press, 1998.

BRADY, H. E.; Sniderman, P. M. "Attitude attribution: a group basis for political reasoning". American Political Science Review, vol. 79, p. 1.071-1.078, 1985.

Braga, M. S. S.; Pimentel JR., J. "Os partidos políticos brasileiros realmente não importam?". Opinião Pública, Campinas, vol. 17, n² 2, p. 271-303, 2011.

BRAMBOR, T.; WiLLIAN, C.; GOLDER, M. "Understanding interaction models: improving empirical analyses". Political Analysis, vol. 14, p. 63-82, 2006.

Campbell, A., et al. The American voter. New York: Wiley, 1960.

CARreirão, Y. S. "Identificação ideológica e voto para presidente". Opinião Pública, Campinas, vol. $12, \mathrm{n}^{\circ} 1$, p. 54-79, 2002.

CONVERSE, P. E. The nature of belief systems in mass public. In: APTER, D. (ed.). Ideology and discontent. New York: Free Press, 1964.

. Attitudes and non-attitudes: continuation of a dialogue. In: TUFTE, E. R. (ed.). The quantitative analysis of social problems. Boston: Addison-Wesley, 1970.

Converse, P. E.; Pierce, R. Political representation in France. Cambridge: Harvard University Press, 1986.

Coppedge, M. A classification of Latin American political parties. Indiana: Kellogg Institute, University of Notre Dame, 1997.

CORRAL, M.; ZeChMEISTER, E. J. "Individual and contextual constraints on ideological labels in Latin America". Comparative Political Studies, vol. 46, p. 675-701, 2013.

Delli CArpini, M. X.; Keeter, S. What Americans know about politics and why it matters. New Haven: Yale University Press, 1996.

Downs, A. "An economic theory of political action in a democracy". The Journal of Political Economy, vol. 65, abr., p. 135-150, 1957.

DUVERger, M. Os partidos políticos. 2a ed. Brasília: Editora UnB, 1980.

ESEB - Estudo Eleitoral Brasileiro. Centro de Estudos de Opinião Pública - Cesop/Unicamp. Disponível em: <http://www.cesop.unicamp.br/site/htm/apre.php> Acesso em: 10 mar. 2012.

Ferreira, D. P.; Batista, C. M.; Stabile, M. "A evolução do sistema partidário brasileiro: número de partidos e votação no plano subnacional 1982-2006". Opinião Pública, Campinas, vol. 14, n², nov., p. 432-453, 2008.

Ferrer, L. E. G.; Velasco, R. Q. "Izquierda y derecha: formas de definirlas, el caso latinoamericano y sus implicaciones". Ediciones Universidad de Salamanca América Latina Hoy, vol. 65, p. 79-105, 2013.

Fleischer, D. Os partidos políticos. In: AvelAR, L.; CinTRA, A. O. Sistema político brasileiro: uma introdução. $2^{a}$ ed. Rio de Janeiro: Konrad-Adenauer-Stiftung; São Paulo: Editora Unesp, p. 303$348,2007$. 
FournieR, P. The uninformed Canadian voter. In: EVERETT, J.; O'NeILL, B. (eds.). Citizen politics: research and theory in Canadian political behavior. Don Mills: Oxford University Press, 2001.

GiLENS, M. "Political ignorance and collective policy preferences". American Political Science Review, vol. 95, p. 379-396, 2001.

GORDON, S. B.; SEGURA, G. M. "Cross-national variation in the political sophistication of individuals: capability or choice?". Journal of Politics, vol. 59, p. 126-147, 1997.

Harbers, I.; VRIes, C. E.; Steenbergen, M. R. "Attitude variability among Latin American publics: how party system structuration affects left/right ideology". Comparative Political Studies, vol. 46, n 8, p. 947-967, 2012.

HigleY, J.; PAKULSKI, J. "Elites, elitism and elite theory: unending confusion?". Artigo apresentado em Research Committee on Political Elites (RC02), no painel "Elite Dilemmas and Democracy's Future", World Congress of the International Political Science Association. Madrid: School of Journalism, jul. 2012.

HUBER, J.; INGLEhART, R. "Expert interpretations of party space and party locations in 42 societies". Sage Publications: Party Politics, vol. 1, n 1, p. 73-111, 1995.

INGLEHART, R.; KLINGEMANN, H. Party identification, ideological preference and the left-right dimension among western mass publics. In: BUdGe, I.; CREWE, I.; FARLIE, D. (eds.). Party identification and beyond. London: Wiley, 1976.

KARL, T. L. "Dilemmas of democratization in Latin America". Comparative Politics, vol. $23, \mathrm{n}^{\circ} 1$, out., p. 1-21, 1990.

KINDER, D. R. Opinion and action in the realm of politics. In: GILBERT, D., et al. (eds.). Handbook of Social Psychology. Oxford University Press, 1998.

KINZO, M. D. "Os partidos políticos: percepções públicas e laços partidários no Brasil". RBCS, vol. 20, n 57, p. 65-81, fev. 2005.

KLINGEMANN, H. D. Measuring ideological conceptualizations. In: BARNES, S. H.; KAASE, M. (eds.). Political action: mass participation in five western democracies. Beverly Hills, California: Sage, 1979.

$\mathrm{KROH}, \mathrm{M}$. "Measuring left-right political orientation: the choice of response format". Public Opinion Quarterly, vol. 71, p. 204-220, 2007.

KRosnick, J. A.; MilbuRn, M. A. "Psychological determinants of political opinion". Social Cognition, vol. 8, p. 49-72, 1990.

KUKLINSKI, J. H., et al. "The political environment and citizen decision making: information, motivation, and policy tradeoffs". American Journal of Political Science, vol. 45, p. 410-424, 2001.

LANE, R. Political ideology. New York: Free Press, 1962.

LAU, R. R. Models of decision-making. In: SEARS, D., et al. (eds.). Oxford Handbook of Political Psychology. Oxford University Press, p. 19-59, 2003.

LAU, R. R.; RedLAwSK, D. P. "Voting correctly". American Political Science Review, vol. 91, p. 585$598,1997$.

LAVAREDA, A. A democracia nas urnas: o processo partidário-eleitoral brasileiro (1945-1964). Rio de 
Janeiro: Revan, Iuperj, 1999.

Lazarsfeld, P.; Berelson, B.; Gaudet, H. The people's choice. New York: Columbia University Press, 1944.

Lodge, M.; Steenbergen, M.; Brau, S. "The responsive voter: campaign information and the dynamics of candidate evaluation". American Political Science Review, vol. 89, p. 309-326, 1995.

LUCAS, K.; SAMUELS, D. A coerência ideológica do sistema partidário brasileiro, 1990-2009. In: POWER, T. J.; ZUCCo JR., C. (orgs.). O Congresso por ele mesmo: autopercepções da classe política brasileira. Editora UFMG: Belo Horizonte, 2011.

LUnA, J. P.; ZeChmeister, E. J. "Political representation in Latin America: a study of elite-mass congruence in nine countries". Comparative Political Studies, vol. 38, n 4, p. 388-416, 2005.

LUPIA, A. "Shortcut versus encyclopedias: information and voting behavior in California insurance reform elections". American Political Science Review, vol. 88, p. 63-76, 1994.

LuPiA, A.; Mccubbins, M. D. The democratic dilemma: can citizens learn what they really need to know? New York: Cambridge University Press, 1998.

LUSKIN, R. C. "Measuring political sophistication". American Journal of Political Science, vol. 31, p. 856-899, 1987.

1990. . "Explaining political sophistication". Political Behavior, vol. 12, n 4, p. 331-361,

From denial to extenuation (and finally beyond): political sophistication and citizen competence. In: KUKLINSKI, J. H. (ed.). Political psychology and political behavior. New York: Cambridge University Press, 2002.

LUSKIN, R. C.; BuLLoCK, J. G. "'Don't know' means 'don't know': DK responses and the public's level of political knowledge". The Journal of Politics, vol. 73, n², p. 547-557, 2011.

LUSKIN, R. C.; FISHKIN, J. S; JOWELL, R. "Considered opinion: deliberative polling in the U.K". British Journal of Political Science, vol. 32, p. 455-487, 2002.

Matsubayashi, T.; TURgeon, M. "Citizen competence and the institutional environment". Trabalho inédito.

Melo, C. R. Retirando as cadeiras do lugar: migração partidária na Câmara dos Deputados (19852002). Belo Horizonte: Editora UFMG, 2004.

Meneguello, R. "Alguns aspectos da lógica de coalizões partidárias. Cidadãos e política: diagnóstico da adesão democrática, comportamento e valores". Brasília: Cepal/Ipea. Texto para discussão Cepal/Ipea 8, 2010.

MondAK, J. J. "Developing valid knowledge scales". American Journal of Political Science, vol. 45, $\mathrm{n}^{\circ} 1$, p. 224-238, 2001.

NARAYAN, S.; KROSNICK, J. A. "Education moderates some response effects in attitude measurement". Public Opinion Quarterly, vol. 60, p. 58-88, 1996.

Neumann, W. R. The paradox of mass politics: knowledge and opinion in the American electorate. Cambridge: Harvard University Press, 1986.

Nicolau, J. "O sistema eleitoral de lista aberta no Brasil". Dados - Revista de Ciências Sociais, Rio 
de Janeiro, vol. 49, n4, p. 689-720, 2006.

Oppo, A. Partidos políticos. In: BobBio, N. Dicionário de política. 5a ed., p. 898-905. Brasília: Editora UnB, 2004.

PAge, B. I.; Shapiro, R. Y.; Dempsey, G. R. "What moves public opinion?". American Political Science Review, vol. 81, n० 1, p. 23-44, mar. 1987.

PAGE, B. I.; ShAPIRO, R. Y. The rational public: fifty years of trends in Americans' policy preferences. Chicago: University Chicago Press, 1992.

PAIVA, D.; TAROUCO, G. S. "Voto e identificação partidária: os partidos brasileiros e a preferência dos eleitores". Opinião Pública, Campinas, p. 426-451, vol. 17, n² 2, nov., 2011.

POPKIN, S. L. The reasoning voter: communication and persuasion in presidential campaigns. Chicago: University of Chicago Press, 1991.

Price, V. Political information. In: Robinson, J. P; ShAVer, P. R; WrightSman, L. S. (eds.). Measures of political attitudes. San Diego: Academic Press, 1999.

SÁEz, M. A. Partidos políticos en América Latina: precisiones conceptuales, estado actual y retos futuros. Barcelona: Ed. Cidob Ediciones, 2004.

SAmuels, D. "Determinantes do voto partidário em sistemas eleitorais centrados no candidato: evidências sobre o Brasil". Dados - Revista de Ciências Sociais, Rio de Janeiro, vol. 40, n 3, 1997.

p. 302-318, 2008.

"A evolução do petismo (2002-2008)". Opinião Pública, Campinas, vol. 14, n², nov.,

SCHOLZ, E.; ZUELL, C. "Item non-response in open-ended questions: who does not answer on the meaning of left and right?". Social Science Research, vol. 41, p. 1.415-1.428, 2012.

SCHUMAN, H.; Presser, S. Questions and answers in attitude surveys: experiments on question form, wording and content. New York: Academic Press, 1981.

Simon, H. A. "Human nature in politics: the dialogue of psychology with political science". American Political Science Review, vol. 79, n², p. 293-304, 1985.

SINGER, A. V. Esquerda e direita no eleitorado brasileiro: a identificação ideológica nas disputas presidenciais de 1989 e 1994. São Paulo: Edusp, 2002.

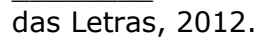

Os sentidos do lulismo: reforma gradual e pacto conservador. São Paulo: Companhia

SMITH, E. R. A. N. "The levels of conceptualization: false measures of ideological sophistication". American Political Science Review, vol. 74, n 3, p. 685-696, set. 1989.

Sniderman, P. M.; Brody, R. A.; TetLock, P. E. Reasoning and choice: explorations in political psychology. Cambridge: Cambridge University Press, 1991.

Sullivan, J. L.; Pierson, J. E; Marcus, G. E. "Ideological constraint in the mass public: a methodological critique and some new findings". American Journal of Political Science, vol. 22, p. 333-349, 1978.

TARouco, G. S.; MADEIRA, R. M. "Partidos, programas e o debate sobre esquerda e direita no Brasil". Revista de Sociologia e Política, vol. 21, n 45, p. 149-165, mar. 2013. 
TURGEON, M. "'Just thinking': attitude development, public opinion, and political representation". Political Behavior, vol. 31, p. 353-378, 2009.

VERGARA, L. G. "Elites, political elites and social change in modern societies". Revista de Sociologia, $n^{\circ} 28$, p. 31-49, 2013.

Wiesehomeier, N.; DoyLe, D. "Attitudes, ideological associations and the left-right divide in Latin America". Journal of Politics in Latin America, vol. 4, $\mathrm{n}^{\circ}$ 1, p. 3-33, 2012.

ZaLLeR, J.; FeLDMAN, S. "A simple theory of the survey response: answering questions versus revealing preferences". American Journal of Political Science, vol. 36, n 3, p. 579-616, ago. 1992.

ZeChmeister, E. J.; CoRRAL, M. "El variado significado de 'izquierda' y 'derecha' en América Latina". Perspectivas desde el Barómetro de las Américas, n 38, 2010.

ZUCCO JR., C. Esquerda, direita e governo: a ideologia dos partidos políticos brasileiros. In: PoweR, T. J.; ZuCCO JR., C. (orgs.). O Congresso por ele mesmo: autopercepções da classe política brasileira. Belo Horizonte: Editora UFMG, 2011.

\section{Apêndice}

\section{Estudo Eleitoral Brasileiro (Eseb) 2002}

O Eseb 2002 foi realizado no período de 31 de outubro a 28 de dezembro de 2002, com amostra nacional e representativa da população brasileira maior de 16 anos de idade. A amostra é probabilística sem substituição, com três estágios de seleção (município, setor censitário e domicílio). No total, foram conduzidas 2.513 entrevistas pessoais domiciliares. A margem de erro da pesquisa é de 3 pontos percentuais para mais ou para menos em um intervalo de confiança de $95 \%$.

\section{Estudo Eleitoral Brasileiro (Eseb) 2010}

O Eseb 2010 foi realizado no período de 4 a 20 de novembro de 2010, com amostra nacional e representativa da população brasileira maior de 16 anos de idade. A amostra é probabilística sem substituição, com três estágios de seleção (município, setor censitário e domicílio). No total, foram conduzidas 2.000 entrevistas pessoais domiciliares. A margem de erro da pesquisa é de 2,2 pontos percentuais para mais ou para menos em um intervalo de confiança de $95 \%$.

Variáveis dependentes

Eseb 2002 e Eseb 2010

Variável liberalismo econômico I (Eseb 2002): foi criada a partir da série de perguntas sobre temas econômicos, a qual abrange as variáveis de $p 107 a$ até $p 107 n$. O questionário está organizado da seguinte forma: "Quem deve administrar cada uma dessas atividades no Brasil: educação; saúde; aposentadoria e previdência social; justiça; transporte; rodovias e estradas; fornecimento de água; serviços de esgoto; recolhimento do lixo; energia elétrica; telefone fixo; telefone celular; bancos; e fabricação de carros?". As respostas estão codificadas da seguinte maneira: "Só empresas do governo, 0 ", "Só empresas particulares, 2" e "Ambos: governo e empresas, 1". Conforme essa codificação, criamos uma escala com as 14 perguntas, somando esses valores. Valores maiores indicam maior papel para a iniciativa privada. Portanto, a variável liberalismo econômico I ficou com uma escala de 0 a 28 , a partir dos 14 itens.

Variável liberalismo econômico II (Eseb 2002): foi criada a partir da série de perguntas também sobre temas econômicos, a qual abrange as variáveis de $p 108 a$ até $p 108 g$. O questionário está organizado da seguinte forma: "O governo deve controlar o preço de todos os serviços básicos, como, por exemplo, do transporte? O governo deve dizer tudo o que as empresas têm que fazer, como, por exemplo, quantos banheiros elas têm que ter? Só as empresas, e nunca o governo, têm que treinar a mão de obra e os trabalhadores? O governo deve socorrer as empresas em dificuldades? O governo deve 
definir qual o valor dos salários de todos os funcionários de todas as empresas do Brasil? Só as empresas, e nunca o governo, devem escolher onde construir uma nova fábrica? O governo deve controlar os preços de todos os produtos vendidos no Brasil?". As respostas foram originalmente codificadas da seguinte maneira: "Discorda muito: 1; Discorda um pouco: 2; Nem concorda nem discorda: 3; Concorda um pouco: 4; Concorda muito: 5". A partir dessa organização, a variável liberalismo econômico II foi codificada com uma escala de valores de 7 a 35, a partir dos sete itens. Os valores maiores indicam maior papel para as empresas privadas.

Variável reforma agrária (Eseb 2002): foi criada a partir da variável p147. Criamos uma variável dicotômica na qual 0 representa quem é a favor da desapropriação das terras sem uso e 1 representa quem é contrário à desapropriação.

Variável liberalismo econômico III (Eseb 2010): foi criada a partir das variáveis de v204 a v212. As perguntas estão nesta ordem: "As leis e os impostos do governo impedem as empresas de ter lucros? Para que o país cresça, o governo deveria intervir mais na economia? A privatização das empresas estatais foi boa para o país? É preciso dar mais liberdade para as empresas dispensarem os empregados? O Brasil estaria bem melhor se nós nos preocupássemos menos com que todo mundo seja igual? Nós teríamos menos problemas no Brasil se as pessoas fossem tratadas com mais igualdade? Em um país como o Brasil, é obrigação do governo diminuir as diferenças entre os muito ricos e os muito pobres? $O$ governo deveria oferecer menos serviços públicos para reduzir os impostos? Se o país for rico, não importa que haja muitas desigualdades econômicas e sociais?". Construímos uma escala na qual os valores menores indicam maior papel para o governo. Os itens foram recodificados da seguinte maneira: "concorda muito" com a intervenção do governo assumiu o valor 0 e "discorda muito", o valor 4 . A variável liberalismo econômico III, dessa forma, tem uma escala com valores de 0 a 36, a partir dos nove itens. Valores maiores indicam apoio às empresas privadas.

Variável redistribuição (Eseb 2010): foi criada a partir das variáveis v221 ("Tudo o que a sociedade produz deveria ser distribuído entre todos, com a maior igualdade possível?") e v222 ("Não basta garantir a igualdade de oportunidades. O governo deve também limitar o enriquecimento daqueles que ganham demais?"). Construímos uma escala na qual os valores menores indicam maior papel para o governo. Os itens foram recodificados da seguinte maneira: "concorda totalmente" com a intervenção do governo assumiu o valor 0 e "discorda totalmente", o valor 3. A variável redistribuição, dessa forma, tem uma escala com valores de 0 a 6, a partir dos dois itens. Da mesma forma, os valores maiores indicam apoio às empresas privadas.

Tabela A1

Variáveis independentes - Eseb 2002 e 2010

\begin{tabular}{|c|c|c|c|c|c|c|c|c|c|c|}
\hline & \multicolumn{3}{|c|}{ Eseb 2002} & & & \multicolumn{5}{|c|}{ Eseb 2010} \\
\hline & Média & D. $-P$. & Mín. & Máx. & $\mathrm{N}$ & Média & D. $-P$. & Mín. & Máx. & $\mathrm{N}$ \\
\hline Ideologia & 5,3 & 3,5 & 0 & 10 & 1.883 & 6,3 & 3,2 & 0 & 10 & 1.104 \\
\hline Idade & 39 & 16,5 & 16 & 94 & 2.514 & 41 & 15,7 & 17 & 93 & 1.999 \\
\hline Gênero & 0,5 & 0,5 & 0 & 1 & 2.514 & 0,5 & 0,5 & 0 & 1 & 2.000 \\
\hline Educação & 0,1 & 0,3 & 0 & 1 & 2.514 & 0,1 & 0,3 & 0 & 1 & 2.000 \\
\hline Sofisticação & 2,1 & 1,6 & 0 & 9 & 2.514 & 6,2 & 2,8 & 0 & 13 & 2.000 \\
\hline
\end{tabular}

Fonte: Elaboração dos autores com base em dados do Eseb 2002 e 2010. 


\section{Resumo}

\section{Ideologia e comportamento político no eleitorado brasileiro}

Este artigo aborda o papel das ideologias esquerda e direita sobre o comportamento político do eleitorado brasileiro, com foco na constrição que essas ideologias devem gerar sobre suas preferências políticas. Em outras palavras, avalia se o eleitor estrutura suas atitudes políticas em consonância com a ideologia de que diz ser adepto. Usando dados de survey do Estudo Eleitoral Brasileiro (Eseb), os achados indicam que parte significativa do eleitorado do Brasil nem se autoposiciona ideologicamente. Pior ainda, a ideologia declarada por poucos eleitores não constringe suas preferências políticas. Seguramente, a grande maioria dos eleitores não conhece a complexidade envolta no antagonismo programático de cada lado do espectro ideológico. Concluise, portanto, que as ideologias não são importantes para o comportamento político do eleitorado brasileiro.

Palavras-chave: ideologia; atitudes políticas; opinião pública; sofisticação política; preferências políticas

\section{Abstract \\ Ideology and political behavior in the Brazilian electorate}

This article explores the role of ideology (left and right) in the Brazilian mass electorate. Specifically, we are interested in examining how ideology constrains the political preferences of Brazilians. Or, said differently, this article explores if Brazilians make use of ideology to structure their political preferences. Using data from the Brazilian Electoral Study Collection (Eseb), we find that many Brazilian voters do not place themselves on a left-right ideological scale when asked to. Moreover, among those voters that place themselves on a left-right ideological scale, we find that ideology does not structure their political preferences. In other words, ideology does not constrain political preferences. To be sure, the notions of left and right do not mean much for the Brazilian electorate.

Keywords: ideology; political attitudes; public opinion; political sophistication; political preferences

\section{Resumen}

Ideología y comportamiento político del electorado en Brasil

En este artículo se analiza el papel de las ideologías de izquierda y de derecha en el comportamiento político del electorado brasileño, centrándose en la constricción que se espera que estas ideologías generen sobre las preferencias políticas. En otras palabras, se mide si el votante estructura sus actitudes políticas en consonancia con la ideología de la que pretende ser adepto. Utilizando datos de la encuesta del Estudio Electoral Brasileño (Eseb), los resultados indican que una parte significativa del electorado de Brasil no se ubica ideológicamente. Peor aún, la ideología declarada por unos cuantos votantes no constriñe sus preferencias políticas. Sin duda, la gran mayoría de los votantes no conocen la complejidad que implica el antagonismo programático de ambos lados del espectro ideológico. Concluimos, por tanto, que las ideologías no son importantes para el comportamiento político del electorado brasileño.

Palabras clave: ideología; actitudes políticas; opinión pública; sofisticación política; preferencias políticas

\section{Résumé}

Idéologie et comportement politique de l'électorat brésilien

Dans cet article, nous examinons le rôle des idéologies de droite et de gauche sur le comportement 
politique de l'électorat brésilien. Plus précisément, l'article a pour objectif d'évaluer comment l'idéologie définit les préférences politiques des Brésiliens. Une analyse quantitative des données de sondage de l'Étude électorale brésilienne (Eseb) démontre que peu de Brésiliens savent se positionner sur l'échelle gauche-droite. Même parmi les électeurs qui parviennent à le faire, on remarque que leur positionnement idéologique n'explique en rien leurs préférences politiques. Assurément, une grande majorité des électeurs n'est pas consciente de la complexité comprise dans I'antagonisme programmatique de chaque côté du spectre idéologique. En d'autres mots, l'idéologie ne semble pas définir les préférences politiques des électeurs brésiliens et les notions de gauche et de droite ont peu de sens pour l'électorat de façon générale.

Mots-clés: idéologie; attitudes politiques; opinion publique; sophistication politique; préférences politiques

Artigo submetido à publicação em janeiro de 2015. Versão final aprovada em agosto de 2015. 